\title{
A Combined TEM/STEM and Micromagnetic Study of the Anisotropic Nature of Grain Boundaries and Coercivity in Nd-Fe-B Magnets
}

\author{
Gregor A. Zickler, ${ }^{1}$ Josef Fidler, ${ }^{1}$ Johannes Bernardi, ${ }^{2}$ Thomas Schrefl, ${ }^{3}$ and Ahmad Asali \\ ${ }^{1}$ Institute of Solid State Physics, TU Wien, Wiedner Hauptstrasse 8-10, 1040 Vienna, Austria \\ ${ }^{2}$ University Service Center for Transmission Electron Microscopy, TU Wien, Wiedner Hauptstrasse 8-10, 1040 Vienna, Austria \\ ${ }^{3}$ Center for Integrated Sensor Systems, Danube University Krems, Viktor Kaplan Str. 2 E, 2700 Wiener Neustadt, Austria \\ Correspondence should be addressed to Josef Fidler; josef.fidler@tuwien.ac.at
}

Received 11 October 2016; Accepted 29 November 2016; Published 15 January 2017

Academic Editor: Jamal Berakdar

Copyright ( 2017 Gregor A. Zickler et al. This is an open access article distributed under the Creative Commons Attribution License, which permits unrestricted use, distribution, and reproduction in any medium, provided the original work is properly cited.

\begin{abstract}
The nanoanalytical high resolution TEM/STEM investigation of the intergranular grain boundary phase of anisotropic sintered and rapidly quenched heavy rare earth-free Nd-Fe-B magnet materials revealed a difference in composition for grain boundaries parallel (large Fe-content) and perpendicular (low Fe content) to the alignment direction. This behaviour vanishes in magnets with a high degree of misorientation. The numerical finite element micromagnetic simulations are based on the anisotropic compositional behaviour of GBs and show a decrease of the coercive field with an increasing thickness of the grain boundary layer. The magnetization reversal and expansion of reversed magnetic domains primarily start as Bloch domain wall at grain boundaries parallel to the $c$-axis and secondly as Néel domain wall perpendicular to the $c$-axis into the adjacent hard magnetic grains. The increasing misalignment of grains leads to the loss of the anisotropic compositional behaviour and therefore to an averaged value of the grain boundary composition. In this case the simulations show an increase of the coercive field compared to the anisotropic magnet. The calculated coercive field values of the investigated magnet samples are in the order of $\mu_{0} H_{c J}=1.8 \mathrm{~T}-2.1 \mathrm{~T}$ for a mean grain boundary thickness of $4 \mathrm{~nm}$, which agrees perfectly with the experimental data.
\end{abstract}

\section{Introduction}

Sintered and rapidly quenched $\mathrm{Nd}-\mathrm{Fe}-\mathrm{B}$ magnets with a high coercive field and energy density product are widely used for large scale applications, such as in wind turbines and electric powered automotive devices. The outstanding hard magnetic properties are controlled by the size, composition, and misalignment of the hard magnetic grains and by the distribution of various nonmagnetic and soft magnetic phases. During the past 3 decades a large number of microstructural investigations of rare earth (RE) permanent magnets have revealed a detailed knowledge of the influence of the complex, multiphase microstructure, especially near grain boundaries on the coercivity of the magnets $[1,2]$. Analytical electron microscopy studies have shown that the $\mathrm{Nd}$-rich grain boundary phase with about $10 \mathrm{~nm}$ thickness limits the coercivity of Nd-Fe-B magnets [3]. It is fairly well known that the coercive field is increased by the addition of small amounts of dopant elements, such as $\mathrm{Al}$ [4], Ga [5], and $\mathrm{Cu}$ [6], which influence the wetting behaviour [7] of the liquid phase during sintering or hot working process and therefore influences the magnetic decoupling of the grains. After cooling from high temperature the formation of additional $\mathrm{Nd}$ containing intergranular phases like $\mathrm{Nd}_{6} \mathrm{Fe}_{13} \mathrm{M}_{1}$, for $\mathrm{M}=\mathrm{Al}$, $\mathrm{Ga}, \mathrm{Cu}$ (delta-phase), $\mathrm{Nd}_{3}(\mathrm{Ga}, \mathrm{Fe})+\mathrm{Nd}_{5}(\mathrm{Ga}, \mathrm{Fe})_{3}$, and $\mathrm{NdCu}$ or $\mathrm{NdCu}_{2}$ occurs [8]. The better separation and decoupling of the hard magnetic grains leads to the enhancement of the coercivity of the magnets. The replacement of the Ndrich intergranular phase by new dopant-containing phases improves the corrosion resistance of the magnet.

The aim of the present paper is to determine the influence of the grain size, orientation of grains, and nanocomposition 
TABLE 1: Magnetic properties of the investigated sintered Nd-Fe-B magnets, measured with a HIRST pulsed field magnetometer.

\begin{tabular}{lccc}
\hline Magnet & $J_{r}[\mathrm{~T}]$ & $J_{s}[\mathrm{~T}]$ & $\mu_{0} H_{c J}[\mathrm{~T}]$ \\
\hline $\mathrm{A}$ & 1.36 & 1.39 & 1.80 \\
$\mathrm{~B}$ & 1.25 & 1.27 & 1.91 \\
\hline
\end{tabular}

of grain boundaries on the coercive field and magnetization reversal behaviour by a combined TEM/STEM and micromagnetic study. Special emphasis was laid on the nanoanalytical characterization of grain boundary junction (GBj) and grain boundary (GB) phases separating the hard magnetic grains with a thickness ranging from $2 \mathrm{~nm}$ to $20 \mathrm{~nm}$ by means of EELS and EDX. The microstructural model structure based on an anisotropic compositional behaviour of GBs parallel and perpendicular to the easy axis of the grains which is used for the numerical micromagnetic simulations has been derived from the detailed nanoanalytical TEM/STEM study.

\section{Materials}

Two HRE free powders $(\mathrm{Nd}, \mathrm{Pr})_{14.9}(\mathrm{Fe}, \mathrm{Co})_{78.5} \mathrm{~T}_{1.0} \mathrm{~B}_{5.6}$ (magnet $\mathrm{A}$ ) and $(\mathrm{Nd}, \mathrm{Pr})_{16.9}(\mathrm{Fe}, \mathrm{Co})_{76.6} \mathrm{~T}_{1.0} \mathrm{~B}_{5.5}$ (Magnet $\mathrm{B}$ ) with $\mathrm{T}=\mathrm{Al}, \mathrm{Ga}, \mathrm{Cu}$ were jet milled in $\mathrm{He}$ atmosphere resulting in a particle size of $1.5 \mu \mathrm{m}$ and an average grain diameter < $2 \mu \mathrm{m}$ after sintering and annealing treatment [9]. After the sintering at the optimized temperatures of $980^{\circ} \mathrm{C}$ (magnet A) and $920^{\circ} \mathrm{C}$ (magnet $\mathrm{B}$ ) and annealing at $500^{\circ} \mathrm{C}$ a density of $7.59 \mathrm{~g} / \mathrm{cm}^{3}$ and $7.58 \mathrm{~g} / \mathrm{cm}^{3}$ for magnets $A$ and $B$, respectively, was achieved. These sintered $\mathrm{Nd}-\mathrm{Fe}-\mathrm{B}$ magnets were provided by Vacuumschmelze GmbH and Co KG, Germany.

In comparison to the sintered magnets a commercially available rapidly quenched 2-phase MQU-F ribbon with a nominal composition $(\mathrm{Pr}, \mathrm{Nd})_{13.6}(\mathrm{Fe}, \mathrm{Co})_{80.2} \mathrm{Ga}_{0.6} \mathrm{~B}_{5.6}[10]$, with $\mu_{0} H_{c J} \approx 2.2 \mathrm{~T}$ and $J_{r}=0.80 \mathrm{~T}$, was provided by Magnequench Technology Centre, Singapore.

The magnetic properties of the sintered magnets were measured in a HIRST pulsed field magnetometer with a field up to $5 \mathrm{~T}$ and are summarized in Table 1 and Figure 1 . A selected area electron diffraction (SAED) tilting experiment in the TEM revealed the average misorientation angle $\vartheta_{0}$, measured on several hard magnetic grains, to be in the range of $9^{\circ}-15^{\circ}$ in magnet $\mathrm{A}$ and $18^{\circ}-28^{\circ}$ in magnet $\mathrm{B}$.

The higher RE content in magnet $\mathrm{B}$ leads to a greater volume fraction of the nonmagnetic GBj phases, causing the decrease of $J_{r}$ in magnet $\mathrm{B}$. The greater misorientation of the easy axis of magnetization of the individual hard magnetic grains further reduces $J_{r}$ of magnet B.

\section{Methods}

The nanoanalytical and structural investigations of the heavy RE-free sintered and rapidly quenched (Pr,Nd)-(Fe,Co)-B permanent magnet materials have been carried out with an analytical field emission transmission electron microscope (TEM) (FEI Tecnai F20) at $200 \mathrm{kV}$, which is equipped with a high angle annular dark field detector (HAADF), a silicon drift energy dispersive X-ray detector (EDX), and a Gatan

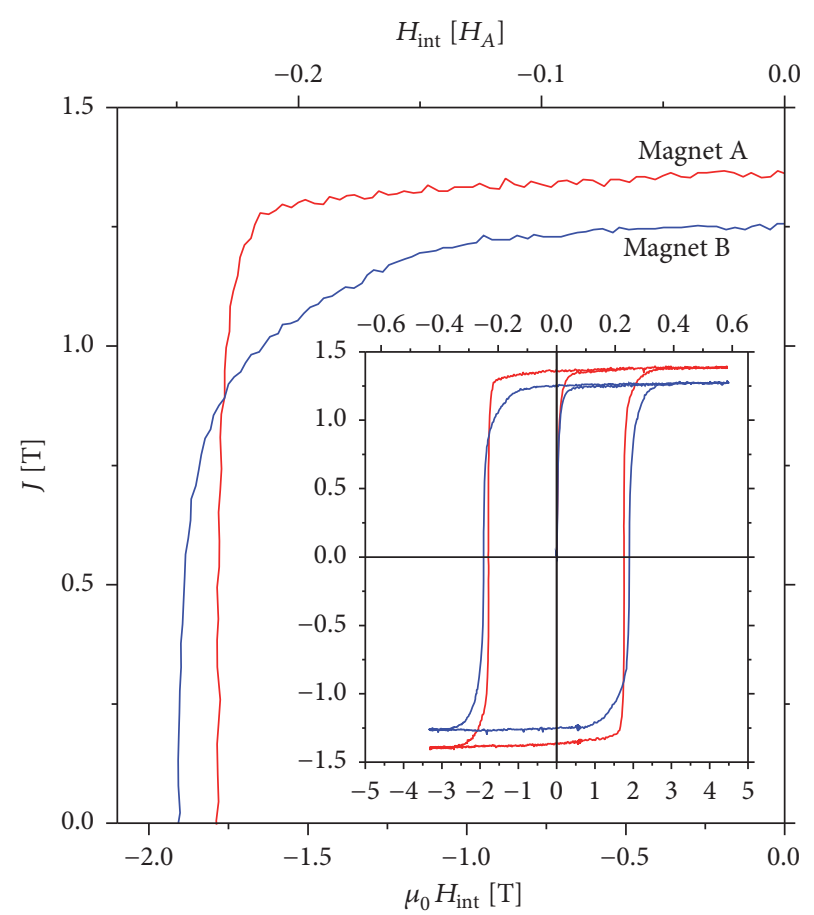

FIgURE 1: Hysteresis curves of magnets A and B measured with a HIRST pulsed field magnetometer.

GIF Tridem image filter and electron energy loss spectrometer (EELS). Focused Ion Beam (FIB) samples for the TEM and scanning TEM (STEM) investigation were produced in an FEI Quanta 200 3D DualBeam-FIB using the liftout technique. The structural investigations were performed with SAED and Fast Fourier Transformation (FFT) of high resolution TEM/STEM (HRTEM) images.

The accurate determination of the relative chemical composition of intergranular phases of TEM specimens with a relative thickness $t / \lambda<0.7$, where $t$ is the absolute specimen thickness and $\lambda$ is the mean free path in the specimen, was conducted with EELS via $k$-factor method. Firstly, $k$ factors of $\mathrm{Nd} / \mathrm{Fe}$ and $\mathrm{Pr} / \mathrm{Fe}$ were calculated from EELS spectra of single crystalline $\mathrm{Pr}_{2} \mathrm{Fe}_{14} \mathrm{~B}$ and $\mathrm{Nd}_{2} \mathrm{Fe}_{14} \mathrm{~B}$ standards. The cubic c- $(\mathrm{Pr}, \mathrm{Nd})_{2} \mathrm{O}_{3} \mathrm{GBj}$ phases were used to acquire the EELS $k$-factor of oxygen relative to $(\mathrm{Pr}, \mathrm{Nd})$. Secondly, the background in the EELS spectra was fitted with a power-law function and subtracted, which resulted in the edge intensities of the elements. Thirdly, the relative atomic composition was calculated from the edge intensities via $k$-factors. This leads to a good accordance of the transition metal (TM) to rare earth (RE) ratio, close to the theoretical value of $14 / 2=$ 87.5 at\%/12.5 at\% (TM/RE) in the EELS line scans. Egerton has shown that the determination of the relative chemical composition via $k$-factor method is accurate for $t / \lambda<1.0$ with an relative error of $\pm 5 \%$ [11]. A narrow integration range of $16 \mathrm{eV}$ was used in measuring the ionization edges of the elements to reduce artefacts of plural scattering and leads to a further reduction of the relative error. An optimized background model was used to measure the $\mathrm{Nd}-\mathrm{M}_{4,5}$ ionization edge due to its close vicinity to the $\operatorname{Pr}-\mathrm{M}_{4,5}$ edge [12]. 


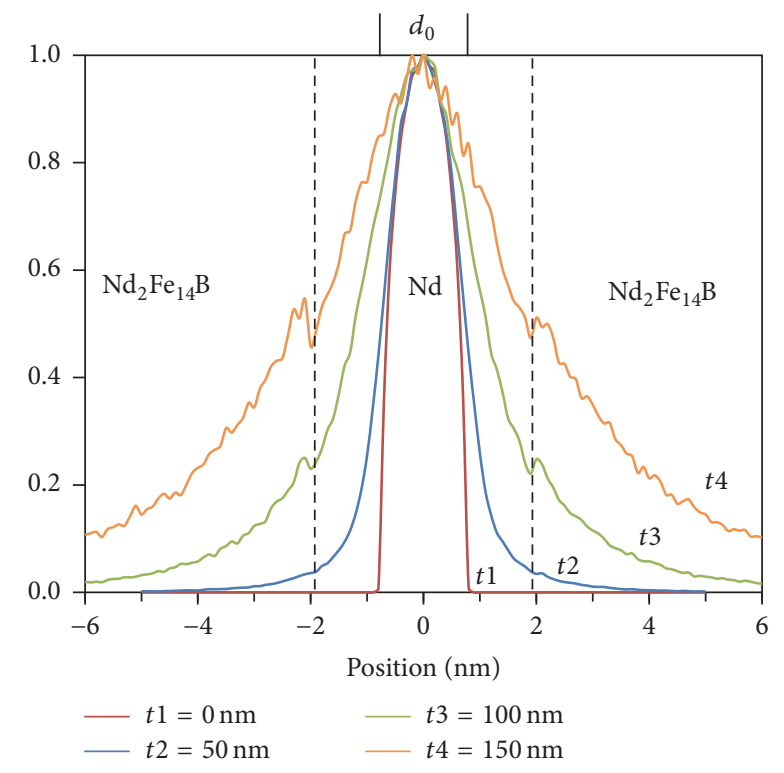

FIGURE 2: Electron density of the electron beam at the bottom surface of the TEM specimen, showing the electron beam broadening of a $1.5 \mathrm{~nm}\left(d_{0}\right.$, red curve) wide beam with a semiconvergence angle of $6 \mathrm{mrad}$, which is focused on the surface of the $4 \mathrm{~nm}$ thick neodymium $\mathrm{GB}$, which is surrounded by two $\mathrm{Nd}_{2} \mathrm{Fe}_{14} \mathrm{~B}$ grains in the TEM specimen with varying thickness. Significant broadening of the incident electron beam occurs at a sample thickness $>50 \mathrm{~nm}$.

Precise precautions were taken to avoid the development of an oxidized layer on the surface of the TEM specimens.

With a given beam shape two factors limit the spatial resolution of an EELS experiment, the broadening of the electron beam in the TEM specimen due to inelastic scattering events, and the orientation of the GB surface relative to the incident electron beam. Monte Carlo simulations of the broadening of an $200 \mathrm{keV}$ electron beam were performed on a $4 \mathrm{~nm}$ thick neodymium GB, surrounded by two $\mathrm{Nd}_{2} \mathrm{Fe}_{14} \mathrm{~B}$ grains, for various sample thicknesses using the software package 3D CASINO v.3.2 [13]. The significant broadening of the electron beam with a sample thickness above $50 \mathrm{~nm}$ is shown in Figure 2. The alignment of the GB surface parallel to the incident electron beam is in the order of $\pm 5^{\circ}$. Therefore up to $15 \%$ of the electrons, which are focused on the GB and are entering the EELS spectrometer, traveled through the adjacent $\mathrm{Nd}_{2} \mathrm{Fe}_{14} \mathrm{~B}$ grains in the TEM specimen with a thickness of $50 \mathrm{~nm}$.

The greatest advantage of EELS with respect to EDX on the analysis of the chemical composition of thin GBs is the much higher yield of the inelastic scattering events. The collection efficiency of the electron spectrometer is typically in the range of $20 \%-50 \%$ and only a few percent of the isotropic emitted characteristic X-rays can be detected by the EDX detector [14]. Since the possibility of obtaining a chemical spectrum purely from the GB drops significantly with rising sample thickness, it is crucial to have a thin specimen $(<50 \mathrm{~nm})$. The small yield of the EDX detector pushes the dwell time for each spot in the line scan up to several seconds, where else a dwell time of approximately one second is sufficient in EELS experiments. The major problem with a long dwell time is that the specimen drift may significantly alter the chemical data. Another benefit of EELS over EDX is the higher energy resolution, which is adventitious for the analysis of light elements like oxygen. The dispersion used in the EELS analysis was $0.3 \mathrm{eV} / \mathrm{ch}$ and in the EDX $10 \mathrm{eV} / \mathrm{ch}$. Although new EDX detectors have a far higher quantum efficiency at low energies (below $1000 \mathrm{eV}$ ), due to ultrathin windows or windowless design, EELS is still more accurate in this energy range.

The numerical micromagnetic simulations were carried out with the finite element software package FEMME, a hybrid finite element/boundary element method code [15, 16]. The Landau-Lifshitz-Gilbert equation is being solved in a model structure consisting of several magnetic grains with different misorientation, which are discretized with finite elements [17]. The input parameters for the simulation are the exchange constant $A$, the saturation polarization $J_{s}$, and the uniaxial magnetocrystalline anisotropy constant $K_{1}$. The rotation of the easy axis (direction of $K_{1}$ ) of a volume can be executed by setting the desired values for the polar angle $\vartheta$ and the azimuthal angle $\phi$. Since the magnetocrystalline anisotropy of the GBs is expected to be zero or negligibly small, $K_{1}$ was set to zero in all GBs. Computationally the calculation of the demagnetizing field $H_{\mathrm{mag}}$ is the most intensive part of the simulation. Exact analytical solutions only exist for special geometries, like rotational ellipsoids [18]. The magnetization reversal is strongly influenced by the long range demagnetizing field as well as the direct exchange coupling between neighbouring atomic moments in the hard magnetic grains and soft magnetic grain boundary layers. Besides the exchange and the demagnetizing field, the magnetocrystalline anisotropy and the misorientation of the individual grains also contribute to the resulting magnetization reversal and coercivity. Numerical micromagnetic modeling based on the discretization by finite elements has widely been used to describe the magnetization reversal in nucleation and domain wall pinning controlled hard magnetic materials $[19,20]$.

The hard magnetic Nd-Fe-B grains and the intergranular GB phases were discretized with a $1 \mathrm{~nm}-2 \mathrm{~nm}$ mesh size, where the mesh tessellation was chosen in a way to ensure that the smallest GB volume has at least one central node surrounded with the nearest neighbors corresponding to GB material. The magnetic properties of GBs in sintered Nd-Fe$B$ permanent magnets play a crucial role for the nucleation of reversed magnetic domains as shown in our previous publications [21,22]. In order to study the anisotropic nature of the chemical composition of the GBs we distinguished between $x$-GBs $\left(\approx 0^{\circ}\right), y$-GBs $\left(\approx 90^{\circ}\right)$, and $z$-GBs $\left(\approx 45^{\circ}\right)$ depending on the angle between the [001] direction of the adjacent grains and the surface normal of the GB. The 8-G model structure in Figure 3(a) consists of eight cubic $\mathrm{Nd}_{2} \mathrm{Fe}_{14} \mathrm{~B}$ grains with an edge length of $50 \mathrm{~nm}$. We considered that the layer of $x$ and $y$-GBs separating the grains may vary in range of $2 \mathrm{~nm}-$ $12 \mathrm{~nm}$; to study the influence of GB thickness on magnetic properties of the structure, we performed calculations for the cases when GBs were $2,4,5,8,10$, and $12 \mathrm{~nm}$ thick. This simplified model structure with cubic grains was used to 


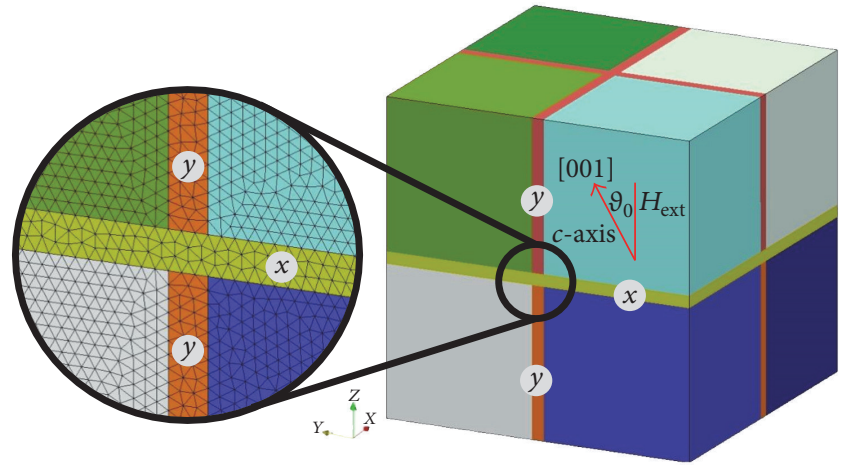

(a)

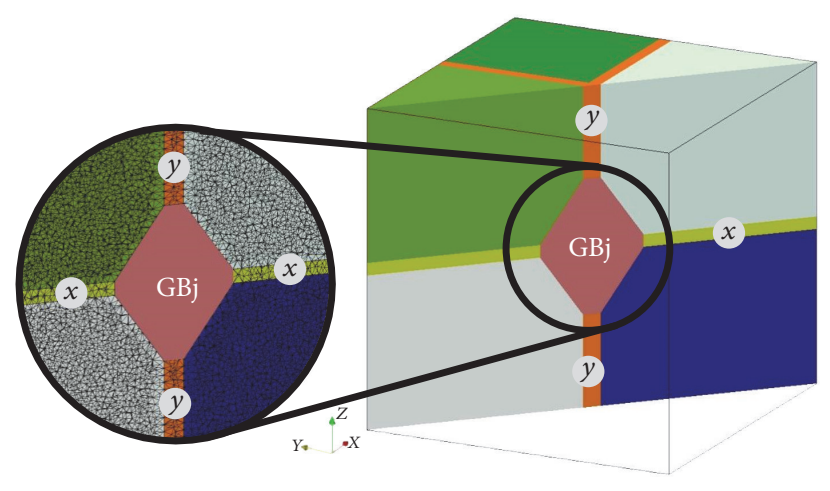

(b)

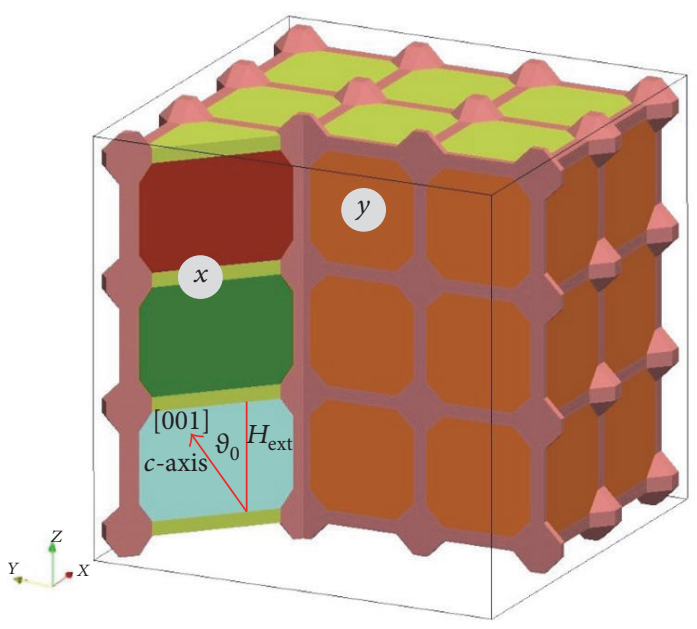

(c)

Figure 3: (a) 8-G finite element model structure consisting of $8 \mathrm{Nd}-\mathrm{Fe}-\mathrm{B}$ grains ( $50 \mathrm{~nm}$ edge, $2 \mathrm{~nm}$ mesh size) misaligned by $\vartheta_{0}$ and separated by $6 \mathrm{~nm}$ thick $x$ - and $y$-GBs ( $2 \mathrm{~nm}$ mesh size); (b) cut of the 8-G-GBj model structure with a truncated octahedron GBj with a height of $44 \mathrm{~nm}$ in the center of the model structure; (c) cut of the 27-G-GBj model structure consisting of 27 grains ( $30 \mathrm{~nm}$ edge, $2 \mathrm{~nm}$ mesh size) separated by $4 \mathrm{~nm}$ thick $x$ - and $y$-GB and GBj and grain boundary edges.

get a clear distinction of the influence of different magnetic properties of $x$ - and $y$-GBs on the hysteretic properties. In addition to this model structure the 8-G-GBj model structure in Figure 3(b) with a truncated octahedral GBj in the center of the model structure was simulated. To obtain a distribution of the misorientation angle $\vartheta_{0}$ representing a real magnet the 27-G-GBj model structure in Figure 3(c) was created with 27 grains separated by $x$ - and $y$-GBs and nonmagnetic GBj and grain boundary edges. We distinguished between the extreme cases of $\vartheta_{0}=9^{\circ}$ and $28^{\circ}$, respectively.

\section{Results and Discussion}

4.1. TEM/STEM Characterization of Grain Boundaries and Grain Boundary Junctions. The HAADF image of Figure 4 shows an overview of two GBjs surrounded by four hard magnetic $(\mathrm{Pr}, \mathrm{Nd})_{2}(\mathrm{Fe}, \mathrm{Co})_{14} \mathrm{~B}$ grains of the well aligned anisotropic sample A. The easy axis of magnetization [001] of the grains is illustrated with arrows and was measured via SAED patterns and FFTs of HRTEM images, as shown in the magnified image of Figure 5(a). The high order of alignment can be seen in the small angle between the [001] directions of grains 1,2 , and 4 . The GBjs were identified with SAED and FFT of HRTEM images as the cubic c- $(\mathrm{Pr}, \mathrm{Nd})_{2} \mathrm{O}_{3}$ phase $(a=$ $1.108 \mathrm{~nm}, I \overline{a 3}$ (no. 206)) [23]. The easy axis of magnetization of this TEM specimen is in plain and parallel to the [001] directions of the grains. Therefore $x-, y$-, and $z$-GBs can be observed.

The region around GBj-1 is shown in a HRTEM-BF image of Figure 5(a), where the (001) lattice planes of grain 4 are well visible. The crystallographic orientation of the single crystalline $(\mathrm{Pr}, \mathrm{Nd})_{2}(\mathrm{Fe}, \mathrm{Co})_{14} \mathrm{~B}$ grain 4 is proven with the SAED image on the left of Figure 5(a) and on the bottom right the SAED image shows the rather polycrystalline diffraction pattern of the c- $(\mathrm{Pr}, \mathrm{Nd})_{2} \mathrm{O}_{3} \mathrm{GBj}-1$, which was also reported in literature $[1,3,24-27]$. The EELS line scan from a grain over a c- $(\mathrm{Pr}, \mathrm{Nd})_{2} \mathrm{O}_{3} \mathrm{GBj}$ into another grain shows the low $\mathrm{Fe}$ content of a few at $\%$ in the GBj (Figure $5(\mathrm{~b}))$. The $(\mathrm{Pr}+\mathrm{Nd}) / \mathrm{O}$ ratio is in average $2 / 3$ in the $\mathrm{GBj}$, which proves the procedure of obtaining the EELS cross section described in Section 3.

Dopants like $\mathrm{Al}, \mathrm{Ga}$, and $\mathrm{Cu}$ influence the wetting behaviour of the liquid phase during sintering [8]. The 


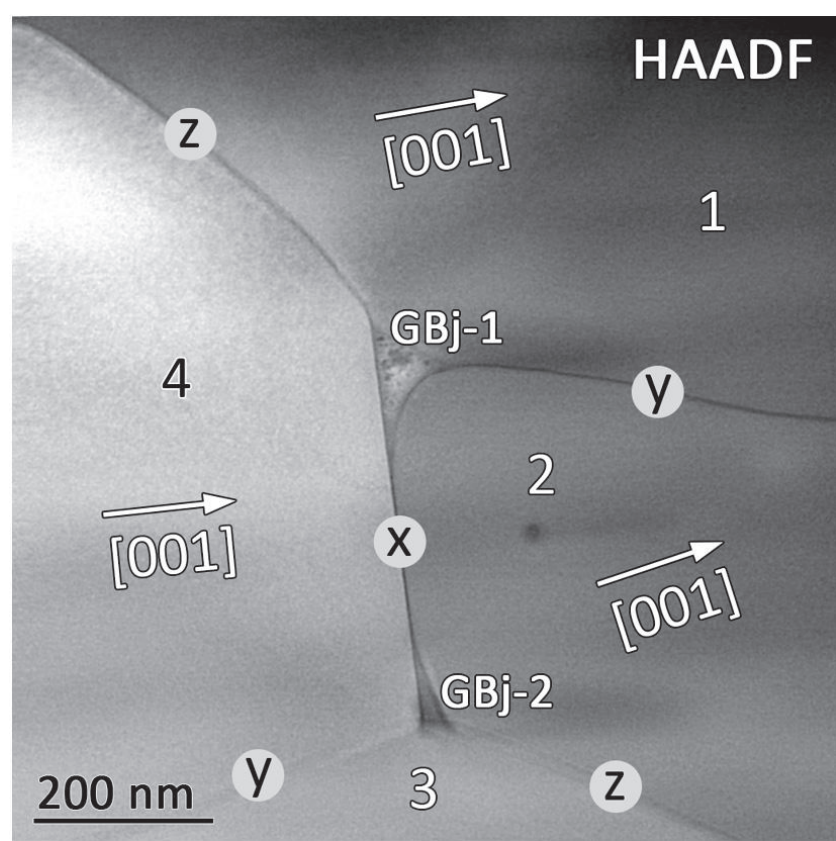

Figure 4: HAADF image of two GBjs surrounded by four $(\mathrm{Pr}, \mathrm{Nd})_{2}(\mathrm{Fe}, \mathrm{Co})_{14} \mathrm{~B}$ grains ([001] direction shown); $x$-, $y$-, and $z$ GBs are visible.

antiferromagnetic $\mathrm{Nd}_{6} \mathrm{Fe}_{13} \mathrm{Al}$ phase was occasionally found near GBjs. The minor amount of the $\mathrm{Ga}$ and $\mathrm{Cu}$ dopants $(<0.4$ at $\%)$ was too low to form separate phases. They were dissolved in the hard magnetic grains partially replacing the Fe-atoms during sintering and annealing treatment.

A high resolution STEM image of two well aligned $(\mathrm{Pr}, \mathrm{Nd})_{2}(\mathrm{Fe}, \mathrm{Co})_{14} \mathrm{~B}$ grains separated by a $4 \mathrm{~nm}$ thick $x$-GB in sample A is shown in Figure 6(a). The (001) lattice planes are visible in the left grain and the (112) in the right grain. The high RE $(\approx 55$ at $\%)$ and low TM $(\approx 40$ at $\%)$ content of the $x-\mathrm{GB}$ is observed in the EELS line scan across the GB in Figure 6(b).

In the HRTEM-BF image in Figure 7(a) (001) is the zone axis and the (001) and (010) lattice planes are visible in the upper grain. In this TEM specimen only $y$-GBs occur, because it was prepared in a way that the surface normal of the sample is parallel to the easy axis of magnetization, which corresponds to the average direction of $c$-axis of the Nd-Fe$\mathrm{B}$ grains. The thickness of the $y$-GB of $6 \mathrm{~nm}$ was measured in the HRTEM-BF image and is in good agreement with the change in chemical composition in the GB in the EELS line scan (Figure 7(b)). The $y$-GB has a lower RE content of $\approx 35$ at $\%$. The measured RE and TM contents of the GBs are in agreement with the results found by three-dimensional atom probe experiments $[28,29]$ of sintered $\mathrm{Nd}-\mathrm{Fe}-\mathrm{B}$ magnets. The anisotropic nature in the chemical composition of GBs parallel and perpendicular to the $c$-axis of the adjacent grains was also reported by Sasaki et al. in 2015 [30]. The chemical composition of $z$-GBs separating misaligned grains is equal to an average value of $x$ - and $y$-GBs (Table 2).

The polycrystalline microstructure of a rapidly quenched MQU-F ribbon with a textured platelet like Nd-Fe-B grain structure with a size ranging from $20 \mathrm{~nm}$ to over $100 \mathrm{~nm}$ is shown in the HRTEM and HAADF images of Figure 8. The hard magnetic Nd-Fe-B grains are clearly separated by $2 \mathrm{~nm}-$ $5 \mathrm{~nm}$ RE rich amorphous GB phase (Figure 8(a)). The difference in the chemical composition of the GBs with respect to the grains leads to a different contrast in the HAADF image (Figure 8(b)). The $c$-axis of elongated grains was always found to be perpendicular to the longer edge of the grains.

The EELS investigation of the GBs, surrounding elongated grains, revealed the anisotropic behaviour of the chemical composition of $x$ - and $y$-GBs with respect to the orientation of the $c$-axis of the elongated grain (Figure 9). Similar to the results of sintered magnets, the $x$-GB has a significantly higher amount of $\mathrm{RE}(\approx 45$ at $\%)$ compared to the $y$-GB $(\approx 30$ at $\%)$.

4.2. Micromagnetic Simulations of the Influence of the GB Composition on the Hysteretic Properties. Nanoanalytical TEM/STEM investigation (Section 4.1) has revealed the $\mathrm{Fe}+\mathrm{Co}$ content of the $x$-GBs to be approximately 40 at $\%$ and the one of the $y$-GBs approximately 60 at $\%$, respectively. Under the consideration of the electron beam broadening and the tilt angle of the GB with respect to the incident electron beam in the TEM the measured EELS concentration of $\mathrm{Fe}+\mathrm{Co}$ was corrected accordingly. The polarization $J_{s}$ of the $x$-GBs used in the simulations is $0.65 \mathrm{~T}(30 \%$ of $\alpha$-Fe) and of the $y$-GBs $1.08 \mathrm{~T}$ ( $50 \%$ of $\alpha$-Fe) (pure $\alpha$-Fe: $J_{s}=2.15 \mathrm{~T} ; A=$ $25 \mathrm{pJ} / \mathrm{m}[31])$. We used the dependence of $A$ on $J_{s}$ described by Kronmüller [32] for the calculation of $A$ of the GBs with varying polarization.

$$
A \propto \varepsilon \cdot J_{s}^{2}
$$

The material constant, $\varepsilon=5.41 \mathrm{Jm}^{-1} \mathrm{~T}^{-2}$, was calculated from the experimentally measured magnetic properties of pure $\alpha$-Fe. We assumed a constant Curie temperature for the calculation of $A$. The values used in the simulation are in good accordance with magnetic properties found in literature. Sepehri-Amin et al. [29] have fabricated a thin film with a polarization of $0.55 \mathrm{~T}$ and with the same chemical composition as the GB of a sintered Nd-Fe-B magnet, which they investigated with three-dimensional atom probe tomography. The magnetic properties of a GB in a sintered $\mathrm{Nd}-\mathrm{Fe}-\mathrm{B}$ magnet was also investigated in a spin-polarized SEM accrediting a polarization of $0.41 \mathrm{~T}-0.48 \mathrm{~T}$ to the $\mathrm{GB}$ [33]. Electron holographic experiments have estimated the polarization of the GBs to be approximately $1.0 \mathrm{~T}$ [34]. Table 2 summarizes the measured concentration and intrinsic magnetic properties used for the micromagnetic simulations.

The results of the micromagnetic hysteretic simulations are summarized in Figure 10. The corresponding magnetization patterns during the reversal are shown in Figure 11. The decrease of $H_{c J}$ with rising GB thickness can be attributed to the greater volume of the soft magnetic GB phase (Figure 10). This is in accordance with published simulated results [38]. The nucleation of reversed magnetic domains in the GB phase accounts for the gradual decay of the polarization in the region between the remnant state and the coercive field. The difference of the coercive field of the 8-G-GBj model structure with a $4 \mathrm{~nm}$ GB compared to $H_{c J}$ of the $8-\mathrm{G}$ model 


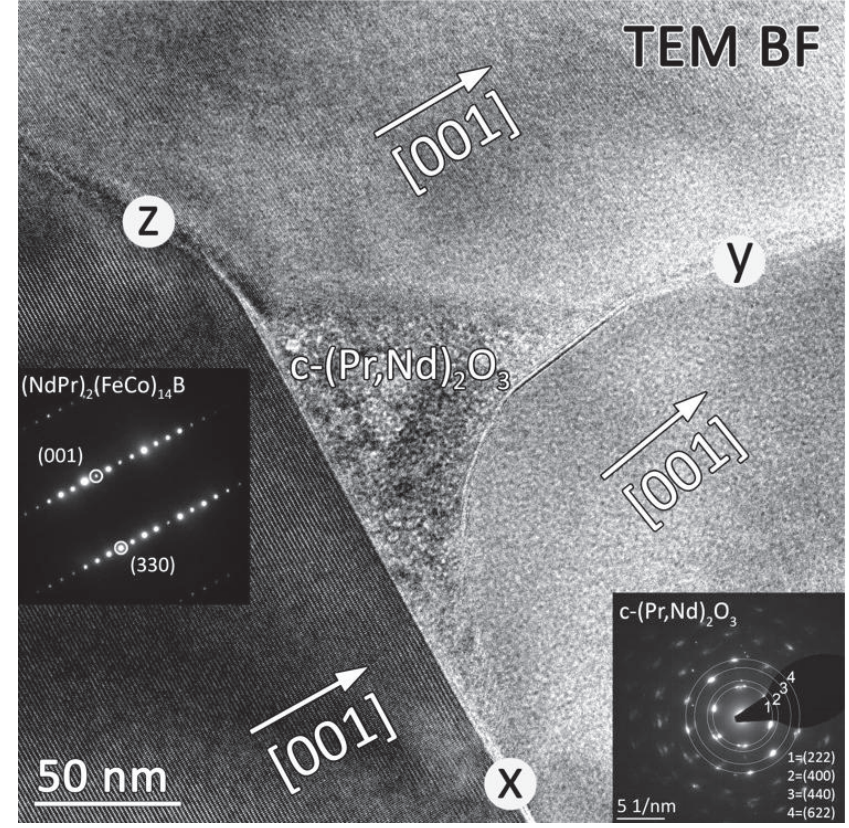

(a)

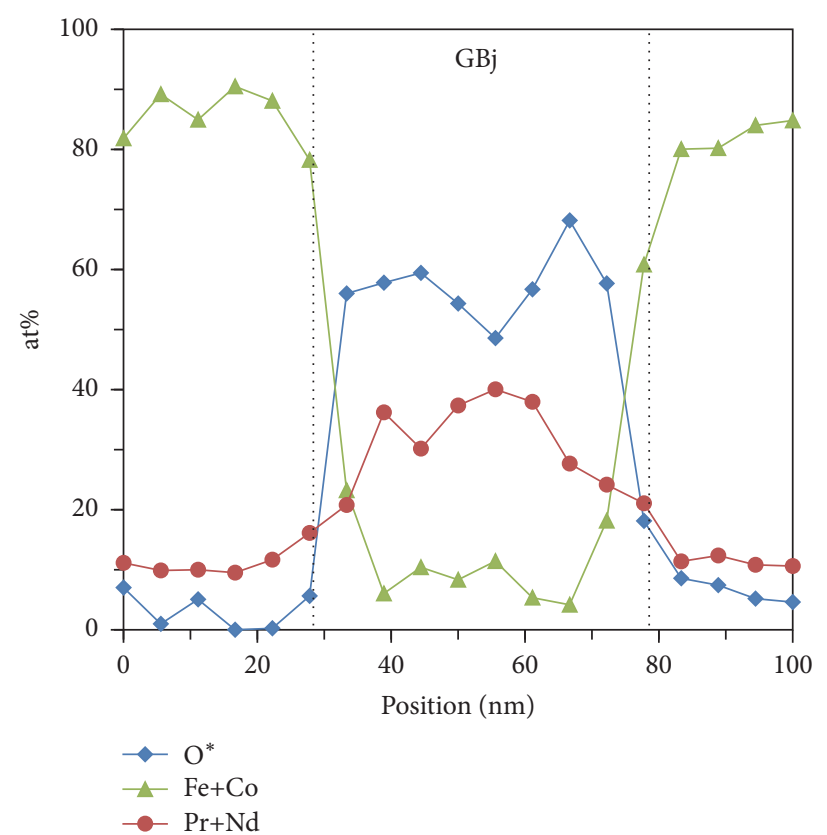

(b)

Figure 5: (a) TEM BF showing the c-(Pr,Nd) ${ }_{2} \mathrm{O}_{3}$ GBj-1, also visible in Figure 4, and SAED images identify the phases; (b) EELS line scan over the $\mathrm{GBj}$, low Fe content $(\approx 5$ at $\%$ ), high $\mathrm{RE}$, and $\mathrm{O}$ (ratio $\approx 2 / 3) ; \mathrm{O}^{*}$ : the oxygen content was corrected (from the measured value) due to surface oxidation of the TEM specimen.

TABLE 2: Measured chemical composition of the occurring phases in magnet A determined by EELS and the magnetic parameters used in the micromagnetic simulations.

\begin{tabular}{|c|c|c|c|c|c|c|}
\hline Phase & $\mathrm{Pr}+\mathrm{Nd}[\mathrm{at} \%]$ & $\mathrm{Fe}+\mathrm{Co}$ & $\mathrm{O}^{*}$ & $J_{s}[\mathrm{~T}]$ & $A[\mathrm{pJ} / \mathrm{m}]$ & $K_{1}\left[\mathrm{MJ} / \mathrm{m}^{3}\right]$ \\
\hline $\mathrm{Nd}_{2} \mathrm{Fe}_{14} \mathrm{~B}$ & 12.8 & 87.2 & - & $1.61^{3}$ & $7.70^{3}$ & $4.90^{3}$ \\
\hline$x-\mathrm{GB}$ & 52.3 & 38.2 & 9.5 & 0.65 & $2.25^{4}$ & 0.00 \\
\hline$y-\mathrm{GB}$ & 32.6 & 60.4 & 7.0 & 1.08 & $6.25^{4}$ & 0.00 \\
\hline$(x-y \text {-avr. })^{1}$ & 42.4 & 49.3 & 8.3 & 0.86 & $4.00^{4}$ & 0.00 \\
\hline$z-\mathrm{GB}^{2}$ & $37.2-48.4$ & $44.5-56.0$ & $0.0-15.2$ & - & - & - \\
\hline $\mathrm{GBj}$ & 31.8 & 10.9 & 57.3 & 0.00 & 0.00 & 0.00 \\
\hline
\end{tabular}

${ }^{1}$ Calculated average of the chemical composition of the $x$ - and $y$-GBs. ${ }^{2}$ Measured values (EELS) depending on the angle of neighboring Nd-Fe-B grains.

${ }^{3}$ Reference: [35-37]. ${ }^{4}$ Values of $A$ were calculated with (1).

structure $(4 \mathrm{~nm} \mathrm{~GB})$ is around $1 \%$ for $\vartheta_{0}=0^{\circ}$ and increases for larger values of $\vartheta_{0}$ with an increase up to $9 \%$ (for $\vartheta_{0}=$ $\left.20^{\circ}\right)$. The stray field at the center of the $8-\mathrm{G}$ model structure increases with rising values of $\vartheta_{0}$, due to the small distances between the misaligned grains. This contribution to the stray field is attenuated in the $8-\mathrm{G}-\mathrm{GBj}$ model structure due to the nonmagnetic GBj at the center of the model structure.

The reversed magnetic domain first nucleates in the central interception of the $y$-GBs at all simulated GB thicknesses (Figures 11(1) and 11(4)). In the case of an $8 \mathrm{~nm} \mathrm{~GB}$ thickness the reversed magnetic domain propagates along the interception of the $x$ - and $y$-GBs (Figure 112) before formation of domain occurs in a roughly cylindrically shaped volume inside the sample, due to the strong component of the stray field parallel the external magnetic field (Figure 113). The nucleation site of the reversed domain is similar in the model structure with $10 \mathrm{~nm} \mathrm{~GB}$ and occurs at a reduced field compared the model structure with an $8 \mathrm{~nm}$ thick GB (Figure 11(4)). The $10 \mathrm{~nm} \mathrm{~GB}$ thickness is sufficient for the domain to be able to propagate along the interception volumes of the $y$-GBs with the $x$-GBs and not only at the interception of the volumes of the $y$-GBs as in the model structure with $8 \mathrm{~nm}$ GB thickness (Figure 115). The slight hints for this geometry of domain expansion were already seen for the model structure with $8 \mathrm{~nm} \mathrm{~GB}$ walls, yet it is far more developed for the case of $10 \mathrm{~nm}$ GB walls (Figure 112). At a higher external field almost the whole $y$-GBs switches (Figure 116), before the reversed domain starts to propagate into the grains again in a cylindrical shape. The earlier switching of the $y$-GBs with respect to the $x$-GBs is explained with the difference of a Bloch and a Néel domain wall. The reversal of the $y$-GBs acts as a Bloch domain wall which propagates into the neighboring hard magnetic grains. On the contrary the nucleation and reversal of the $x$-GBs starts like 


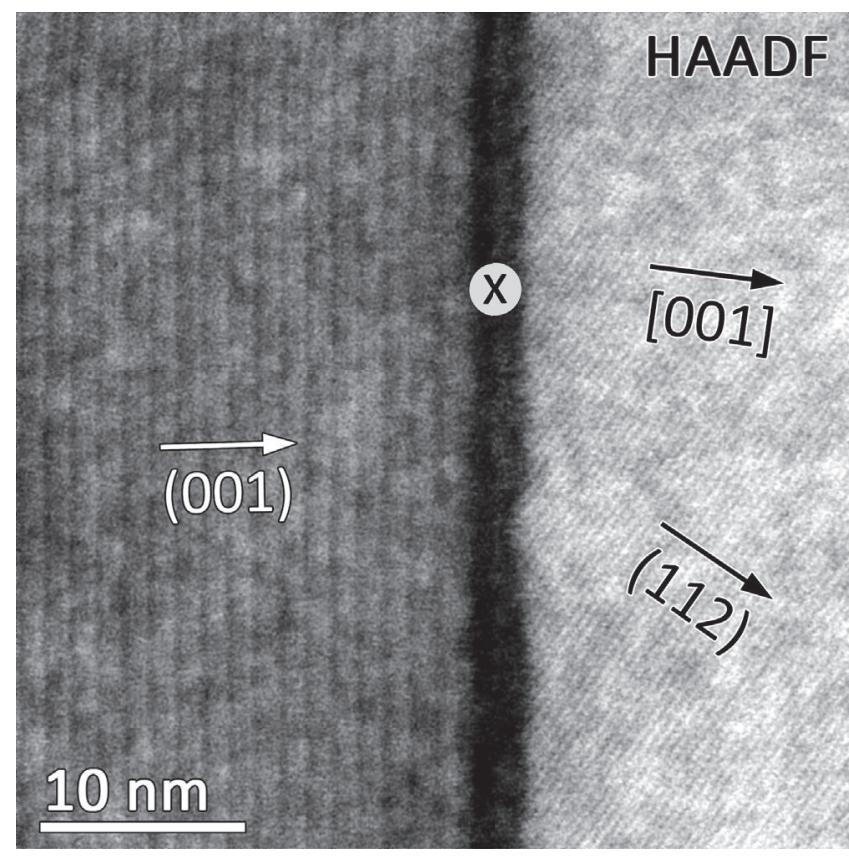

(a)

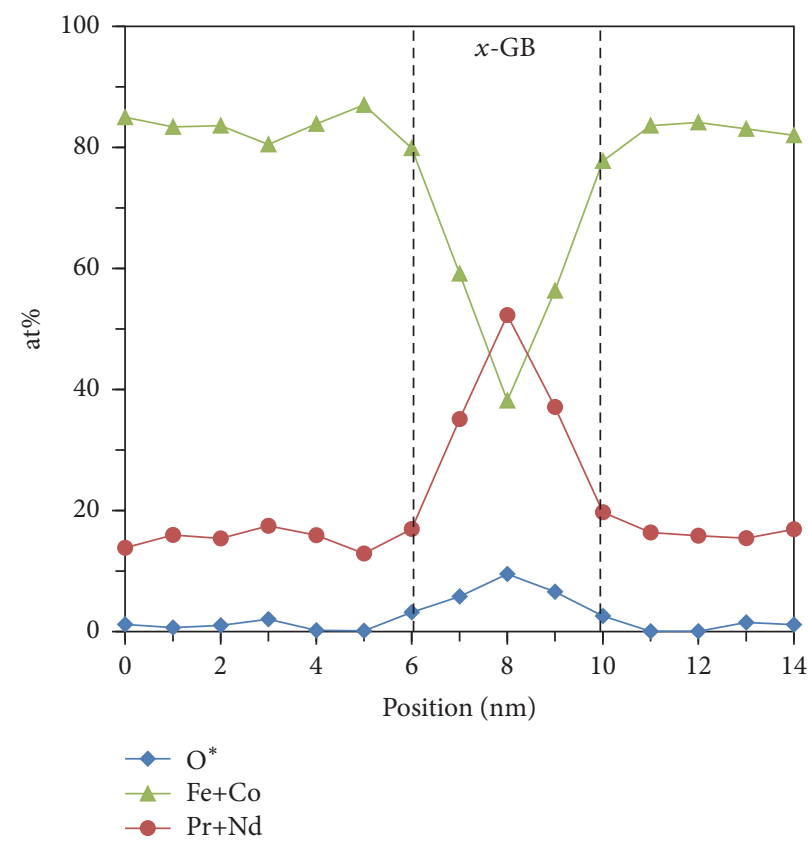

(b)

Figure 6: (a) HAADF image of an $x$-GB, (001) lattice fringes of the left grain, and (112) lattice fringes of the right grain are visible; (b) EELS line scan over the GB in (a); significant rise in the RE concentration in the GB.

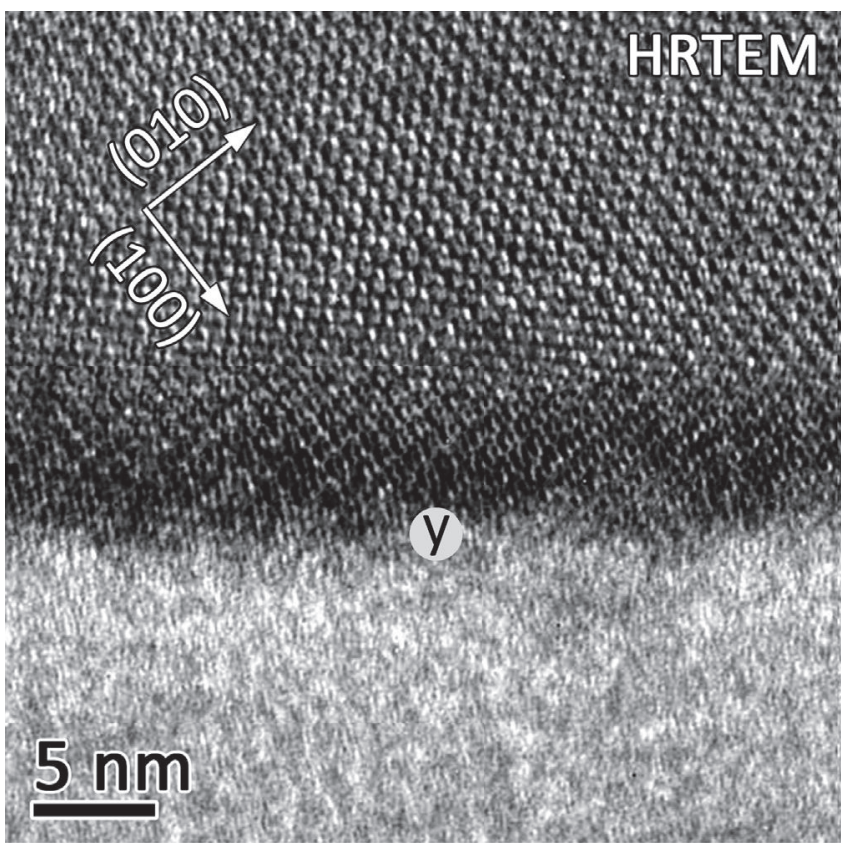

(a)

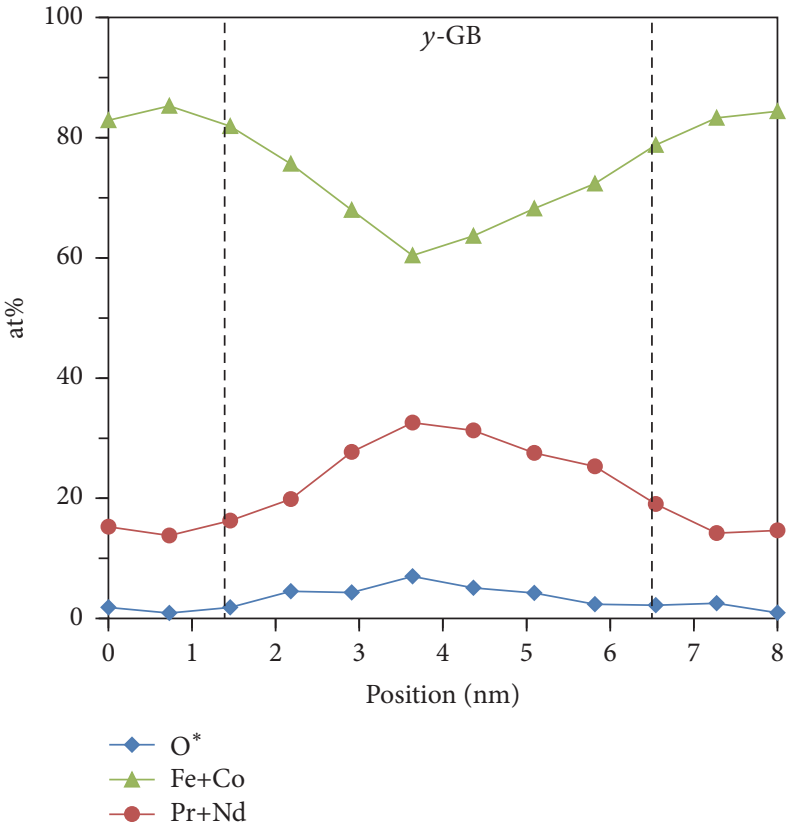

(b)

Figure 7: (a) HRTEM of y-GB, (100) and (010) lattice fringes of the top grain are visible, [001] zone axis; (b) EELS line scan across $y$-GB; a significant increase of RE in the GB found.

a Néel domain wall, leading to a strong stray field contribution along the whole volume of the $x$-GBs [36]. The energy of this stray field is higher than the local influence of the external field. The $x$-GB therefore switches simultaneously with the reversal of the hard magnetic grains. According to the simulation results, there is a marked influence on the resulting coercive field, such as the increase of $H_{c J}$ by $12 \%$ due to the nucleation and reversal processes related the $x$-GBs 


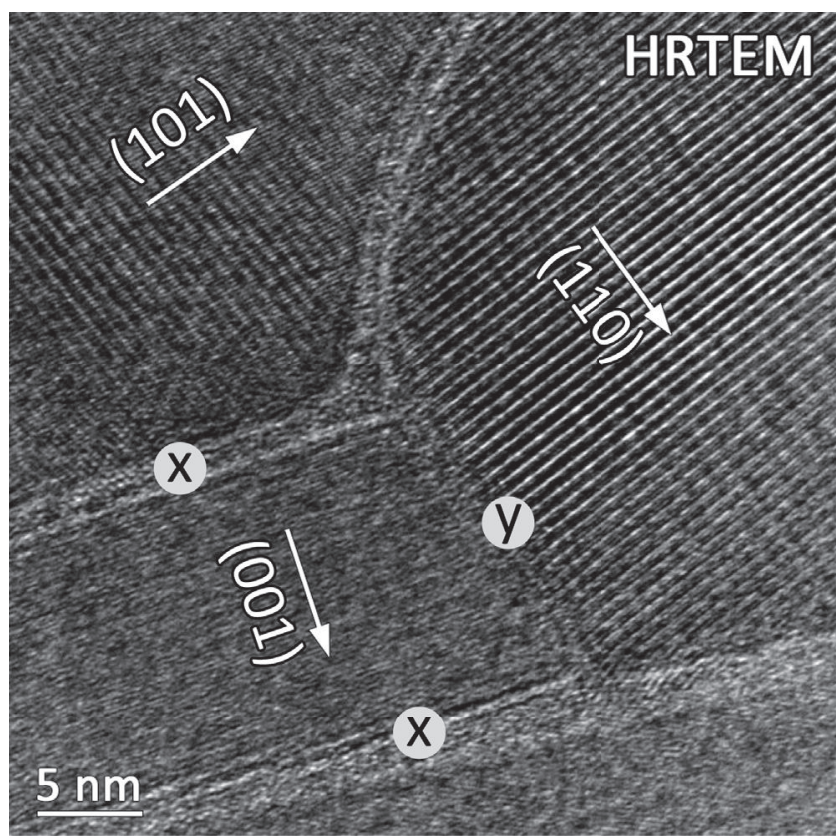

(a)

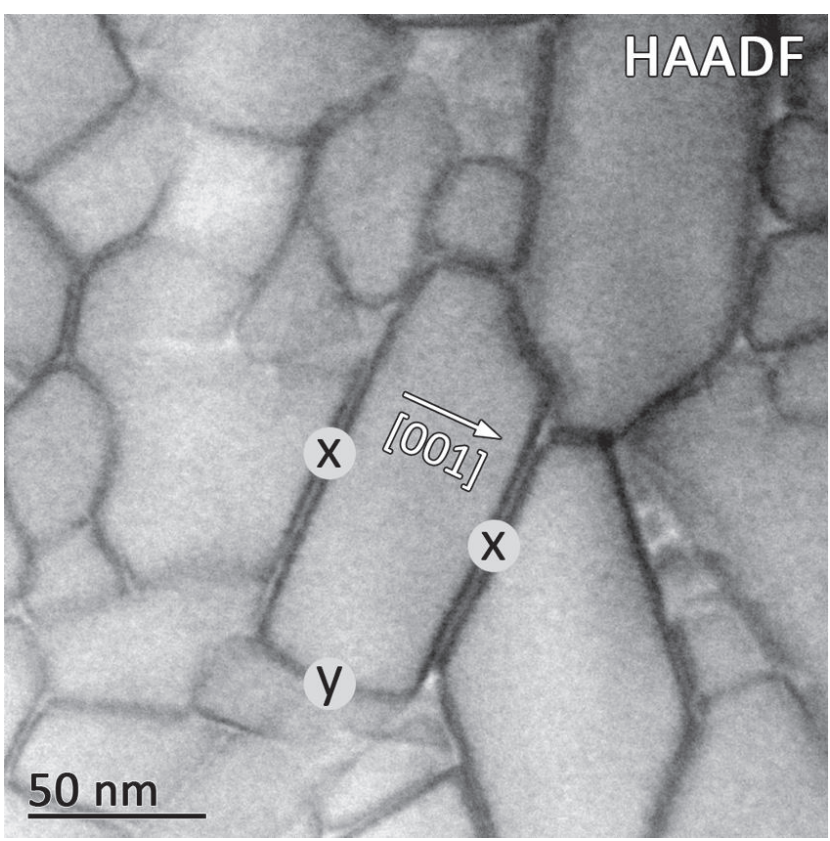

(b)

FIGURE 8: (a) HRTEM image of four Nd-Fe-B grains separated by $x$-, $y$-, and $z$-GBs, (101), (110), and (001) lattice fringes of the grains are visible. (b) HAADF image of the grain, from which the EELS line scans of Figure 9 were taken.

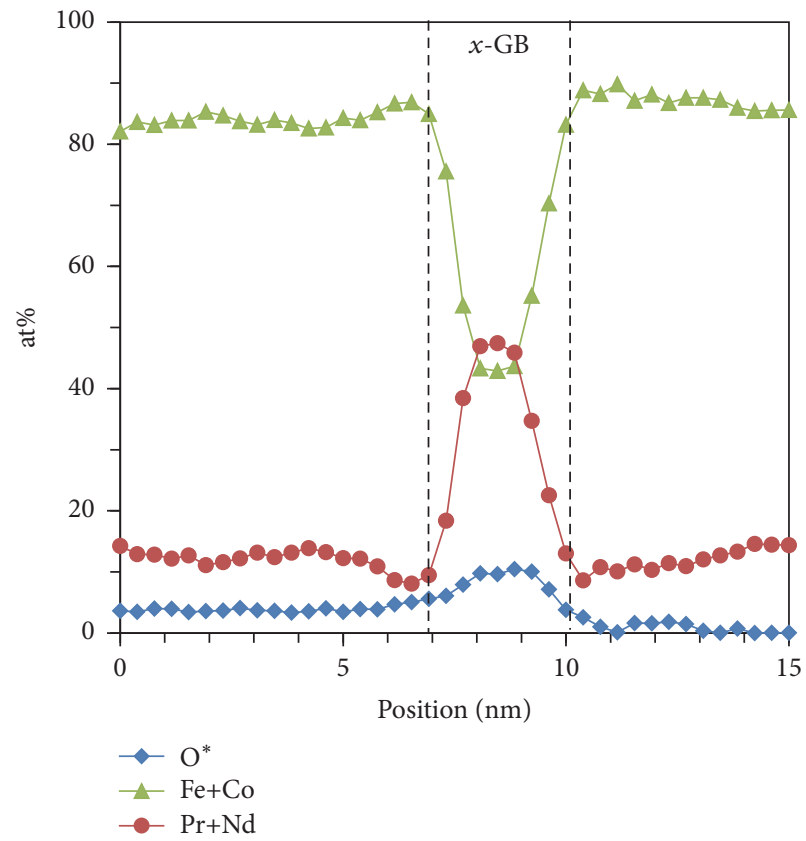

(a)

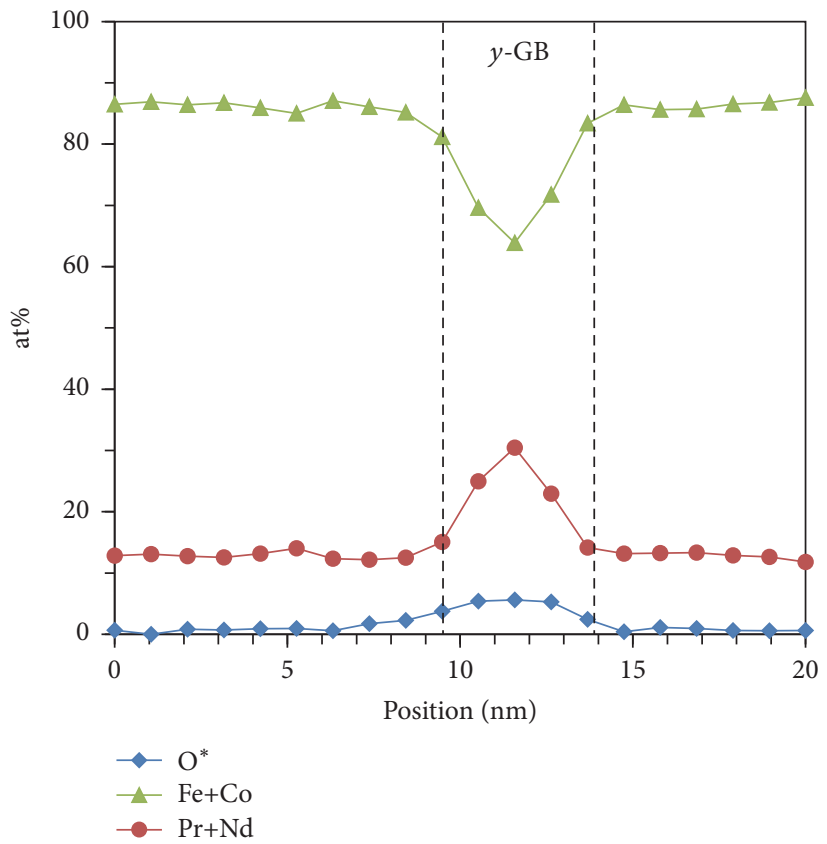

(b)

Figure 9: EELS line scans across $x$-GB (a) and $y$-GB (b) of the elongated grain of Figure 8(b); significant difference in the chemical composition of $x$ - and $y$-GB.

compared to the values of the $y$-GBs. An energy minimizing micromagnetic study predicted a stronger influence of soft magnetic properties of $y$-GBs, with respect to $x$-GBs, but the coercive field values of misaligned simulations were always below the aligned case for various GB properties [39].
Macroscopic hysteretic properties depend primarily on the misorientation of the hard magnetic grains and the thickness and magnetic properties of the GBs. The magnetic properties of the GBs depend on the misalignment angle $\vartheta_{0}$ of the adjacent hard magnetic grains (Table 2). The difference in 


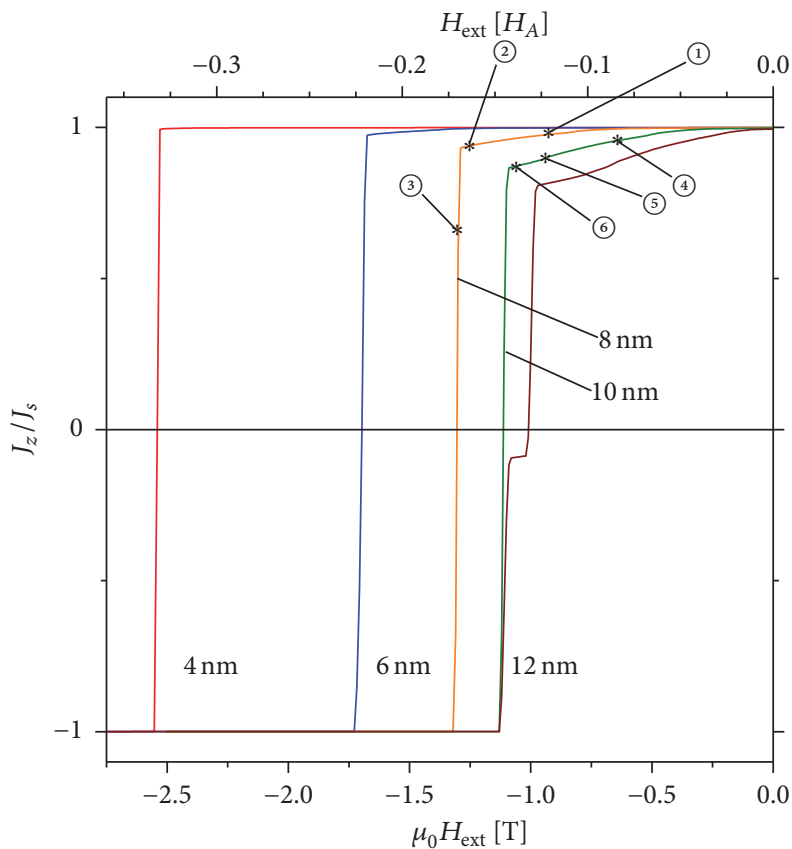

(a)

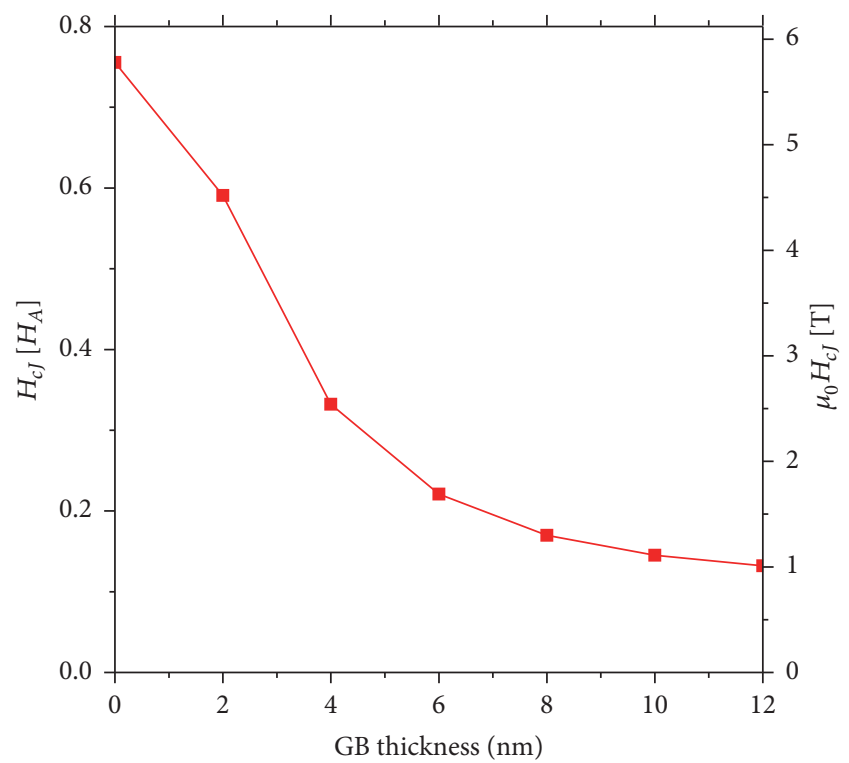

(b)

FIGURE 10: (a) Hysteresis curves of the $8-\mathrm{G}$ model structure with a GB thickness ranging from $4 \mathrm{~nm}$ to $12 \mathrm{~nm}$ and $\vartheta_{0}=0^{\circ}$; points (1)-(6) correspond to the magnetic configuration in Figure 11. (b) Influence of the GB thickness $(0 \mathrm{~nm}-12 \mathrm{~nm})$ on $H_{c j}$ in the 8 -G model structure for $\vartheta_{0}=0^{\circ}$.

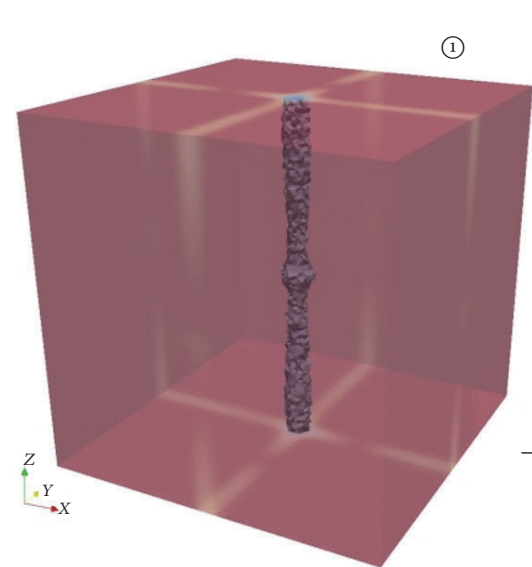

$H_{\text {ext }}=-0.93 \mathrm{~T}\left(-0.122 H_{A}\right)$

(4)

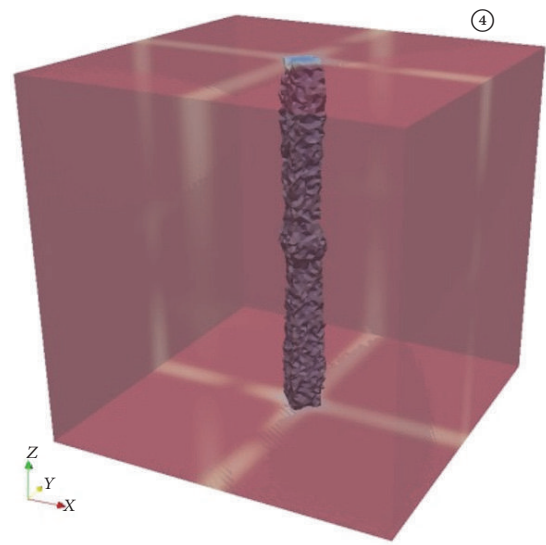

$H_{\text {ext }}=-0.63 \mathrm{~T}\left(-0.082 H_{A}\right)$

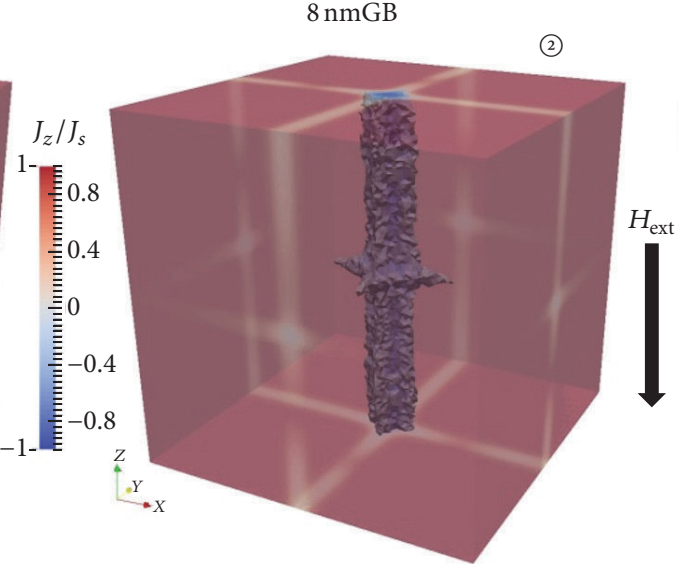

$H_{\text {ext }}=-1.23 \mathrm{~T}\left(-0.161 H_{A}\right)$

$10 \mathrm{nmGB}$

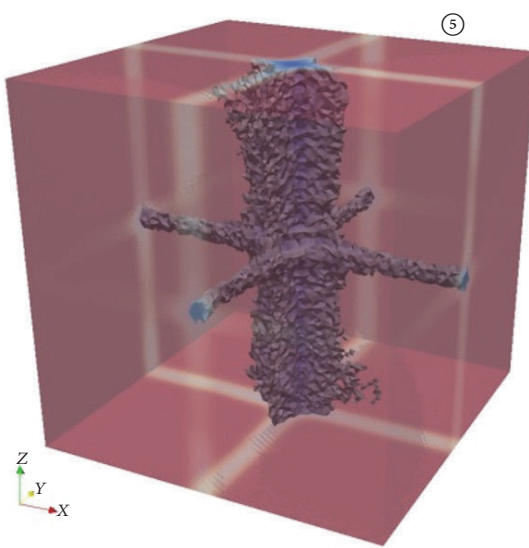

$H_{\text {ext }}=-0.93 \mathrm{~T}\left(-0.122 H_{A}\right)$

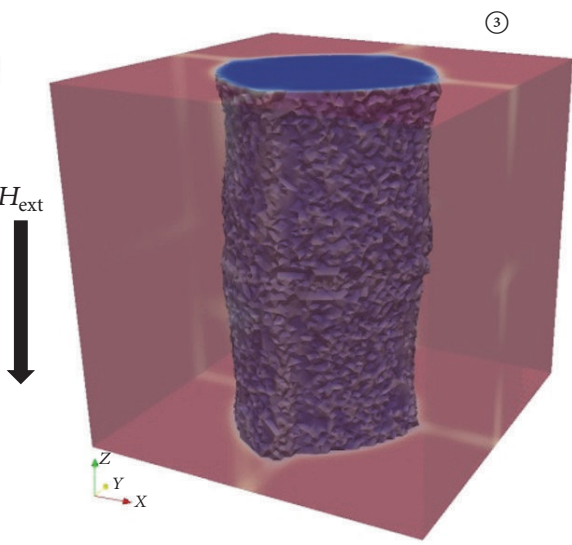

$H_{\text {ext }}=-1.30 \mathrm{~T}\left(-0.170 H_{A}\right)$

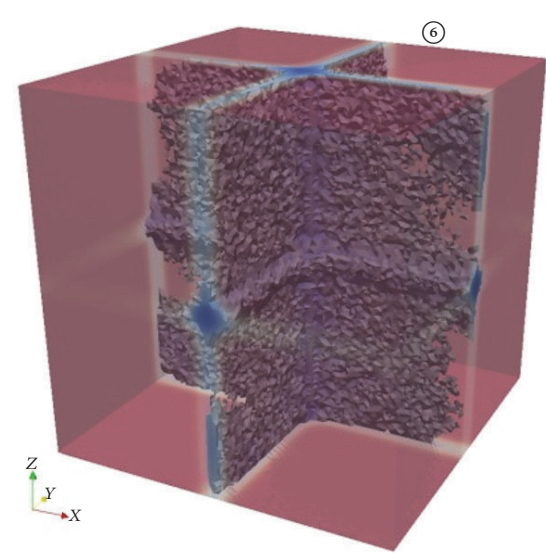

$H_{\text {ext }}=-1.08 \mathrm{~T}\left(-0.141 H_{A}\right)$

FIGURE 11: Visualization of the nucleation and propagation of the reversed magnetic domains in the 8-G model structure with a GB thickness of $8 \mathrm{~nm}$ (1)-(3) and $10 \mathrm{~nm}$ (4)-(6) with $\vartheta_{0}=0^{\circ}$. 


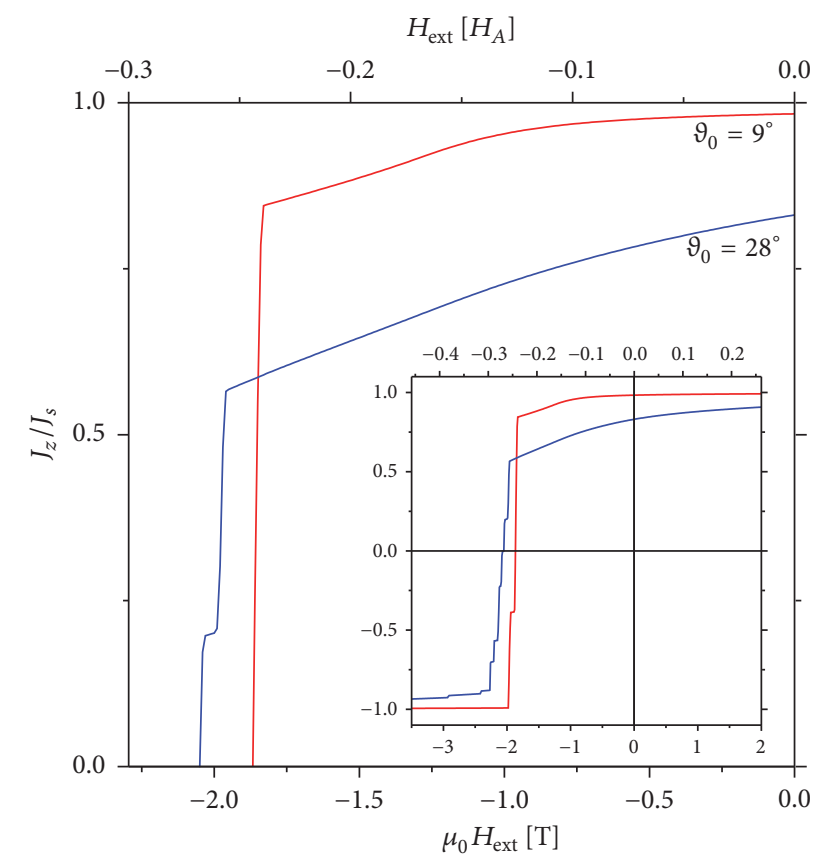

FIGURE 12: Simulated hysteresis curves of the 27-G-GBj model structure with a distribution of the misorientation angle $\vartheta_{0}$ of the hard magnetic grains with an average of $9^{\circ}$ and $28^{\circ}$, respectively. The simulation with the greater misorientation has a higher $H_{c J}$ (by $5 \%$ ).

the magnetic properties of $x$ - and $y$-GBs decreases with rising average misorientation angle $\vartheta_{0}$. The magnetic properties of $x$ - and $y$-GBs, which are listed in Table 2 , correspond to an average misorientation angle $\vartheta_{0}$ of $0^{\circ}$. With an average misorientation of $45^{\circ}$ the properties change to the ( $x$-y-avr.) values. Starting from the increased value of $H_{c J}$ of the misaligned magnet $B$ in the demagnetization curve (Figure 1 ) we used the 27-G-GBj model structure (Figure 3(c)) to simulate the coercive field comparing a misaligned $\left(\vartheta_{0}=28^{\circ}\right)$ and an aligned magnet $\left(\vartheta_{0}=9^{\circ}\right)$ with different $J_{s}$ values of the GB phase according to TEM measurements. The increased coercive field of the misaligned model structure (Figure 12), compared to the aligned one, is in good agreement with the measured data. The small discrepancy between the measured and simulated coercive fields can be attributed to the uniform size of distribution grains $[40,41]$ and GBs and other microstructural features, which were not taken into account in the simulated model structure, for example, soft magnetic inclusions in the grains, which can act as a nucleation site for reversed magnetic domains [42], and a reduction of the magnetocrystalline anisotropy of the hard magnetic grains near intergranular phases as a molecular dynamic study revealed [27, 43].

\section{Conclusion}

Two fine-grained sintered heavy RE-free magnets with different misalignment degree and RE content and an isotropic rapidly quenched magnet were characterized in a nanoanalytical TEM/STEM study. We identified the anisotropic nature in the chemical composition of the GBs parallel and perpendicular to the alignment direction. The Fe content in GBs, where the GB's surface normal is parallel to the [001] direction of the adjacent grains $(x-\mathrm{GB})$, is approximately 30 at $\%-40$ at $\%$. If the GB's surface normal is perpendicular to the [001] direction of the adjacent grains ( $y$-GB), the Fe content rises to 50 at $\%-60$ at $\%$. This anisotropic behaviour of the chemical composition in GBs was also observed on elongated grains in the rapidly quenched sample.

Micromagnetic finite element simulations have shown the influence of the anisotropic magnetic properties of the GBs on the coercivity. Finite element models structures consisting of 8 hard magnetic cubic $\mathrm{Nd}-\mathrm{Fe}-\mathrm{B}$ grains separated by $2 \mathrm{~nm}-12 \mathrm{~nm}$ thick GBs were used to calculate the influence of the GB thickness on coercivity and the reversal process. The reversal in the $x$-GBs resembles a Néel domain wall with a significant contribution to the stray field. $y$-GBs have a stronger influence on the coercivity, since reversed magnetic domains can propagate as the energetically more favorable Bloch domain walls. The center of the GB is more decoupled from the hard magnetic grains as the GB thickness is increased. This leads to a significant reduction in the coercive field with rising GB thickness. The influence of the misorientation angle $\vartheta_{0}$ on the coercive field was simulated in the 27-G-GBj model structure with $\vartheta_{0}=9^{\circ}$ and $28^{\circ}$, respectively. The magnetic properties of the GBs depend on the misorientation of the adjacent grains. The polarization of the $y$-GBs decreases with rising misorientation and the polarization of the $x$-GBs increases. The simulated hysteresis properties were validated by experimental results.

\section{Competing Interests}

The authors declare that there is no conflict of interests regarding the publication of this paper.

\section{Acknowledgments}

The authors are grateful to Drs. M. Katter and K. Uestuener from Vacuumschmelze $\mathrm{GmbH}$ and Co KG for providing the sintered Nd-Fe-B magnet samples and to Dr. D. Brown from Magnequench Technology Centre, Singapore, for providing the rapidly quenched $\mathrm{Nd}-\mathrm{Fe}-\mathrm{B}$ magnet samples.

\section{References}

[1] J. Fidler and K. G. Knoch, "Electron microscopy of Nd-Fe-B based magnets," Journal of Magnetism and Magnetic Materials, vol. 80, no. 1, pp. 48-56, 1989.

[2] J. Fidler, T. Schrefl, S. Hoefinger, and M. Hajduga, "Recent developments in hard magnetic bulk materials," Journal of Physics Condensed Matter, vol. 16, no. 5, pp. S455-S470, 2004.

[3] J. Fidler, "Analytical microscope studies of sintered Nd-Fe-B magnets," IEEE Transactions on Magnetics, vol. 21, no. 5, pp. 1955-1957, 1985.

[4] J. Fidler, K. G. Knoch, H. Kronmüller, and G. Schneider, "Analytical TEM study of Al-doped, 'two-phase' Nd-Fe-B sintered magnets," Journal of Materials Research, vol. 4, no. 4, pp. 806-814, 1989. 
[5] J. Bernardi, J. Fidler, M. Seeger, and H. Kronmuller, "Preparation and TEM-study of sintered Nd18Fe74B6GalNb1 magnets," IEEE Transactions on Magnetics, vol. 29, no. 6, pp. 2773-2775, 1993.

[6] J. Fidler and J. Bernardi, "Transmission electron microscope characterization of cast and hot-worked R-Fe-B: $\mathrm{Cu}(\mathrm{R}=\mathrm{Nd}, \mathrm{Pr})$ permanent magnets," Journal of Applied Physics, vol. 70, no. 10, pp. 6456-6458, 1991.

[7] K. G. Knoch, G. SChneider, E.-T. Henig, H. Kronmüller, and J. Fidler, "Al-doped nd-fe-b permanent magnets: wetting and microstructural investigations," IEEE Transactions on Magnetics, vol. 25, no. 5, pp. 3426-3428, 1989.

[8] J. Fidler, J. Bernardi, and T. Schrefl, "Permanent magnets-new microstructural aspects," Scripta Metallurgica et Materiala, vol. 33, no. 10-11, pp. 1781-1791, 1995.

[9] F. Bittner, T. G. Woodcock, L. Schultz et al., "Normal and abnormal grain growth in fine-grained $\mathrm{Nd}-\mathrm{Fe}-\mathrm{B}$ sintered magnets prepared from He jet milled powders," Journal of Magnetism and Magnetic Materials, 2016.

[10] A. Kirchner, J. Thomas, O. Gutfleisch, D. Hinz, K.-H. Müller, and L. Schultz, "HRTEM studies of grain boundaries in dieupset Nd-Fe-Co-Ga-B magnets," Journal of Alloys and Compounds, vol. 365, no. 1-2, pp. 286-290, 2004.

[11] R. F. Egerton, "The range of validity of EELS microanalysis formulae," Ultramicroscopy, vol. 6, no. 1, pp. 297-300, 1981.

[12] P. Mcguiness, O. Akdogan, A. Asali et al., "Replacement and original magnet engineering options (ROMEOs): a European seventh framework project to develop advanced permanent magnets without, or with reduced use of, critical raw materials," JOM, vol. 67, no. 6, pp. 1306-1317, 2015.

[13] D. Drouin, A. R. Couture, D. Joly, X. Tastet, V. Aimez, and R. Gauvin, "CASINO V2.42-a fast and easy-to-use modeling tool for scanning electron microscopy and microanalysis users," Scanning, vol. 29, no. 3, pp. 92-101, 2007.

[14] R. F. Egerton, Electron Energy-Loss Spectroscopy in the Electron Microscope, Plenum Press, New York, NY, USA, 1996.

[15] T. Schrefl, D. Suess, W. Scholz, H. Forster, V. Tsiantos, and J. Fidler, "Finite element micromagnetics," in Computational Electromagnetics, vol. 28 of Lecture Notes in Computational Science and Engineering, pp. 165-181, Springer, Berlin, Germany, 2003.

[16] T. Schrefl and J. Fidler, "Numerical simulation of magnetization reversal in hard magnetic materials using a finite element method," Journal of Magnetism and Magnetic Materials, vol. 111, no. 1-2, pp. 105-114, 1992.

[17] T. L. Gilbert, "Classics in magnetics a phenomenological theory of damping in ferromagnetic materials," IEEE Transactions on Magnetics, vol. 40, pp. 3443-3449, 2004.

[18] J. A. Osborn, "Demagnetizing factors of the general ellipsoid," Physical Review, vol. 67, no. 11-12, pp. 351-357, 1945.

[19] J. Fidler and T. Schrefl, "Micromagnetic modelling-the current state of the art," Journal of Physics D: Applied Physics, vol. 33, no. 15, pp. R135-R156, 2000.

[20] D. Suess, J. Fidler, K. Porath, T. Schrefl, and D. Weller, "Micromagnetic study of pinning behavior in percolated media," Journal of Applied Physics, vol. 99, no. 8, Article ID 08G905, 2006.

[21] G. A. Zickler, P. Toson, A. Asali, and J. Fidler, "Nanoanalytical TEM studies and micromagnetic modelling of Nd-Fe-B magnets," Physics Procedia, vol. 75, pp. 1442-1449, 2015.
[22] P. Toson, G. A. Zickler, and J. Fidler, "Do micromagnetic simulations correctly predict hard magnetic hysteresis properties?" Physica B: Condensed Matter, vol. 486, pp. 142-150, 2016.

[23] P. Villars and L. D. Calvert, Pearson's Handbook of Crystallographic Data for Intermetallic Phases, vol. 4, ASM International, Materials Park, Ohio, USA, 2nd edition, 1991.

[24] W. Tang, S. Zhou, R. Wang, and C. D. Graham Jr., "An investigation of the Nd-rich phases in the Nd-Fe-B system," Journal of Applied Physics, vol. 64, no. 10, 1988.

[25] D. Lemarchand, P. Vigier, and B. Labulle, "On the oxygen stabilized Nd-rich phase in the Nd-Fe-B (-O) permanent magnet system," IEEE Transactions on Magnetics, vol. 26, no. 5, pp. 2649-2651, 1990.

[26] S. C. Wang and Y. Li, "In situ TEM study of Nd-rich phase in $\mathrm{NdFeB}$ magnet," Journal of Magnetism and Magnetic Materials, vol. 285, no. 1-2, pp. 177-182, 2005.

[27] G. Hrkac, T. G. Woodcock, K. T. Butler et al., "Impact of different Nd-rich crystal-phases on the coercivity of Nd-Fe-B grain ensembles," Scripta Materialia, vol. 70, no. 1, pp. 35-38, 2014.

[28] H. Sepehri-Amin, Y. Une, T. Ohkubo, K. Hono, and M. Sagawa, "Microstructure of fine-grained $\mathrm{Nd}-\mathrm{Fe}-\mathrm{B}$ sintered magnets with high coercivity," Scripta Materialia, vol. 65, no. 5, pp. 396399, 2011.

[29] H. Sepehri-Amin, T. Ohkubo, T. Shima, and K. Hono, "Grain boundary and interface chemistry of an Nd-Fe-B-based sintered magnet," Acta Materialia, vol. 60, no. 3, pp. 819-830, 2012.

[30] T. T. Sasaki, T. Ohkubo, Y. Une, H. Kubo, M. Sagawa, and K. Hono, "Effect of carbon on the coercivity and microstructure in fine-grained Nd-Fe-B sintered magnet," Acta Materialia, vol. 84, pp. 506-514, 2015.

[31] E. Kneller, A. Seeger, and H. Kronmüller, "Ferromagnetismus," in Ferromagnetismus: Mit einem Beitrag Quantentheorie und Elektronentheorie des Ferromagnetismus, E. Kneller, A. Seeger, and H. Kronmüller, Eds., pp. 30-37, Springer, Berlin, Germany, 1962.

[32] H. Kronmüller, "General micromagnetic theory," in Handbook of Magnetism and Advanced Magnetic Materials, vol. 2, chapter 2.1.1, John Wiley \& Sons, Hoboken, NJ, USA, 2007.

[33] T. Kohashi, K. Motai, T. Nishiuchi, and S. Hirosawa, "Magnetism in grain-boundary phase of a $\mathrm{NdFeB}$ sintered magnet studied by spin-polarized scanning electron microscopy," Applied Physics Letters, vol. 104, no. 23, Article ID 232408, 2014.

[34] Y. Murakami, T. Tanigaki, T. T. Sasaki et al., "Magnetism of ultrathin intergranular boundary regions in $\mathrm{Nd}-\mathrm{Fe}-\mathrm{B}$ permanent magnets," Acta Materialia, vol. 71, pp. 370-379, 2014.

[35] R. Skomski and J. M. D. Coey, Permanent Magnetism, Institute of Physics, Bristol, UK, 1999.

[36] H. Kronmüller, "Magnetisierungskurve der Ferromagnetika," in Moderne Probleme der Metallphysik, A. Seeger, Ed., vol. 2, p. 52, Springer, Berlin, Germany, 1966.

[37] R. Skomski, Simple Models of Magnetism, Oxford University Press, New York, NY, USA, 2008.

[38] S. Bance, H. Oezelt, T. Schrefl et al., "Influence of defect thickness on the angular dependence of coercivity in rare-earth permanent magnets," Applied Physics Letters, vol. 104, no. 18, Article ID 182408, 2014.

[39] J. Fujisaki, A. Furuya, Y. Uehara et al., "Micromagnetic simulation of the orientation dependence of grain boundary properties on the coercivity of Nd-Fe-B sintered magnets," AIP Advances, vol. 6, no. 5, Article ID 056028, 2016. 
[40] T. Schrefl, J. Fidler, and H. Kronmüller, "Remanence and coercivity in isotropic nanocrystalline permanent magnets," Physical Review B, vol. 49, no. 9, pp. 6100-6110, 1994.

[41] S. Bance, B. Seebacher, T. Schrefl et al., "Grain-size dependent demagnetizing factors in permanent magnets," Journal of Applied Physics, vol. 116, no. 23, Article ID 233903, 2014.

[42] T. Schrefl, H. Kronmüller, and J. Fidler, "Exchange hardening in nano-structured two-phase permanent magnets," Journal of Magnetism and Magnetic Materials, vol. 127, no. 3, pp. L273L277, 1993.

[43] G. Hrkac, K. Butler, T. G. Woodcock, L. Saharan, T. Schrefl, and O. Gutfleisch, "Modeling of Nd-oxide grain boundary phases in Nd-Fe-B sintered magnets," JOM, vol. 66, no. 7, pp. 1138-1143, 2014. 

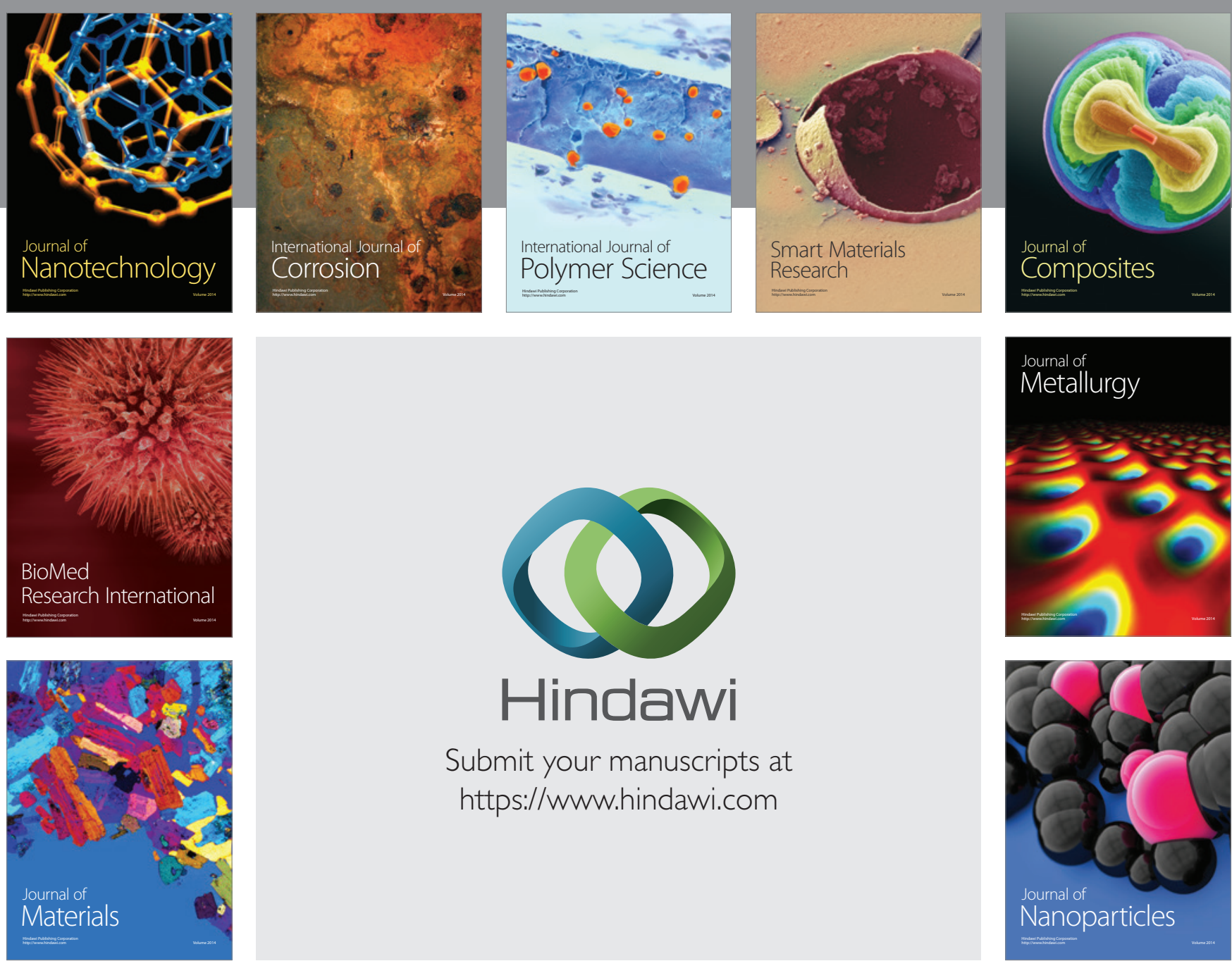

\section{Hindawi}

Submit your manuscripts at

https://www.hindawi.com

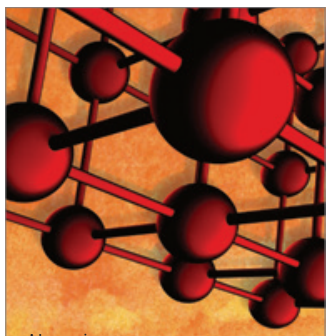

Materials Science and Engineering
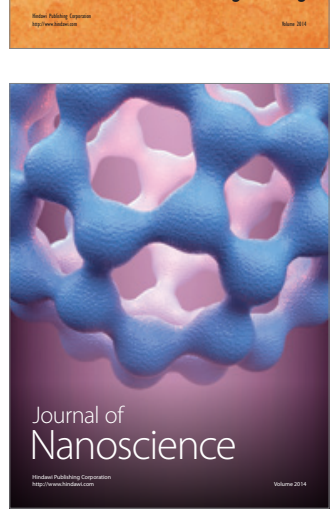
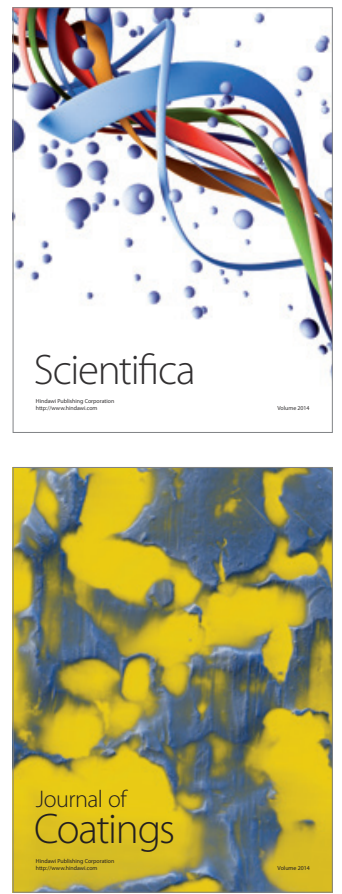
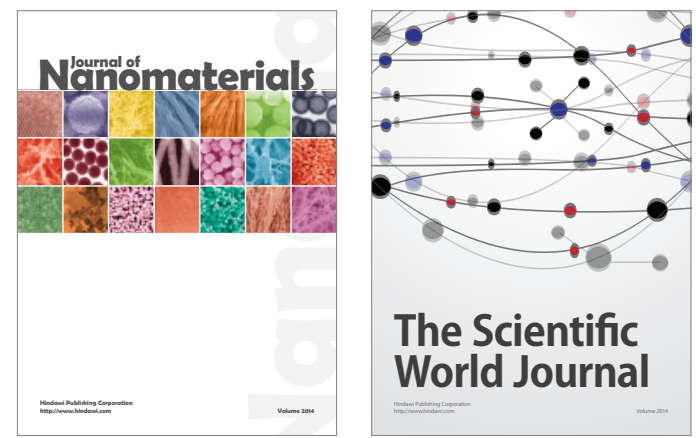

The Scientific World Journal
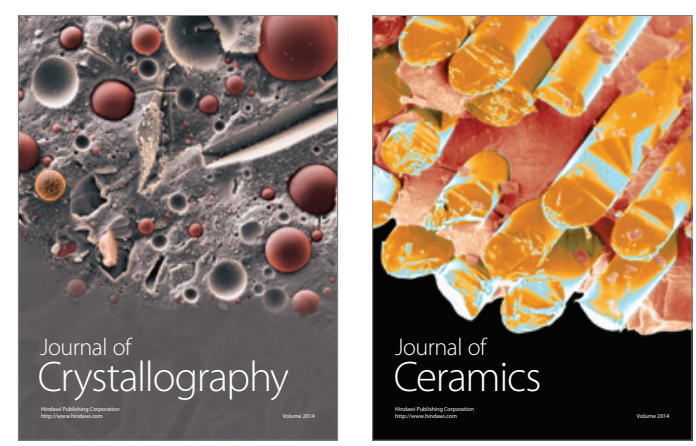
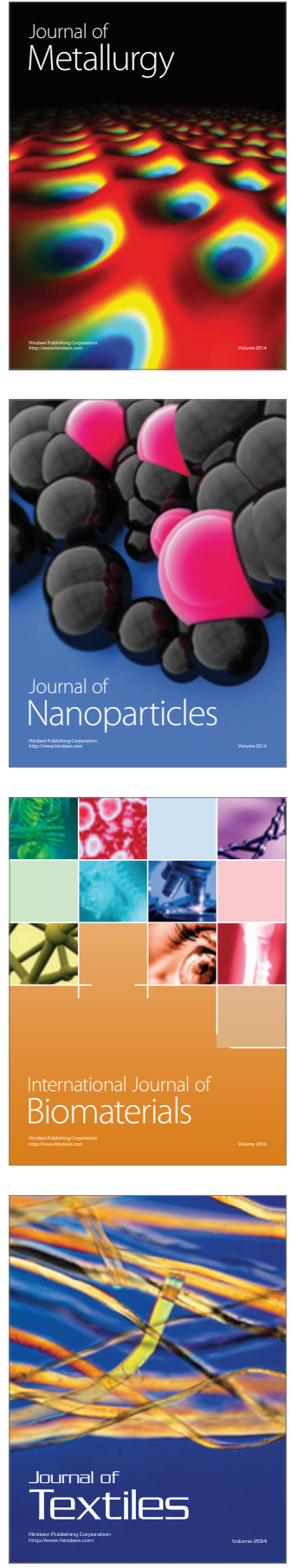